\title{
Fistulization of self-expanding metal stent from right colon into duodenum
}

Colonic obstruction has been reported in $7 \%-29 \%$ of patients with colorectal cancer. Endoscopic placement of a self-expandable metal stent (SEMS) to relieve obstruction is often used for palliation or as a "bridge" to elective surgery [1]. We describe a unique complication of colonic SEMS placement.

An 87-year-old woman presented with anemia, weight loss, and fatigue. She underwent a colonoscopy which revealed a partially obstructing mass at the hepatic flexure; biopsies confirmed adenocarcinoma. CT scan of the abdomen confirmed an "apple core" lesion with no evidence of perforation. The patient underwent placement of a $22 \times 120 \mathrm{~mm}$ colonic SEMS (WallFlex $^{\circledR}$; Boston Scientific, Natick, Mass., USA) without difficulty. Following stent placement she experienced clinical deterioration and increasing diarrhea. Further review of the CT revealed the possibility of duodenal invasion from the hepatic flexure mass ( $\bullet$ Fig. 1 a). An upper endoscopy was performed which revealed fistulization of the colonic SEMS through the hepatic flexure into the second portion of the duodenum. The endoscope was able to transit the fistula through the stent from the duodenum and enter the colon ( Video 1). A CT scan of the abdomen performed following the endoscopy confirmed that the colonic stent extended to the second portion of the duodenum with no evidence of free air ( $\bullet$ Fig.1 b). Surgical options were considered, but due to the patient's deteriorating functional status a palliative approach was chosen.

SEMS are used in the symptomatic management of colonic obstruction. While success rates are high, complications include perforation, migration, and procedure-related mortality [2-4]. Migration of biliary stents resulting in colovaginal fistula has been reported [5]. This is the first report to our knowledge of a colonic

\section{Video 1}

Endoscopy from the duodenum via the self-expanding metal stent into the transverse colon.
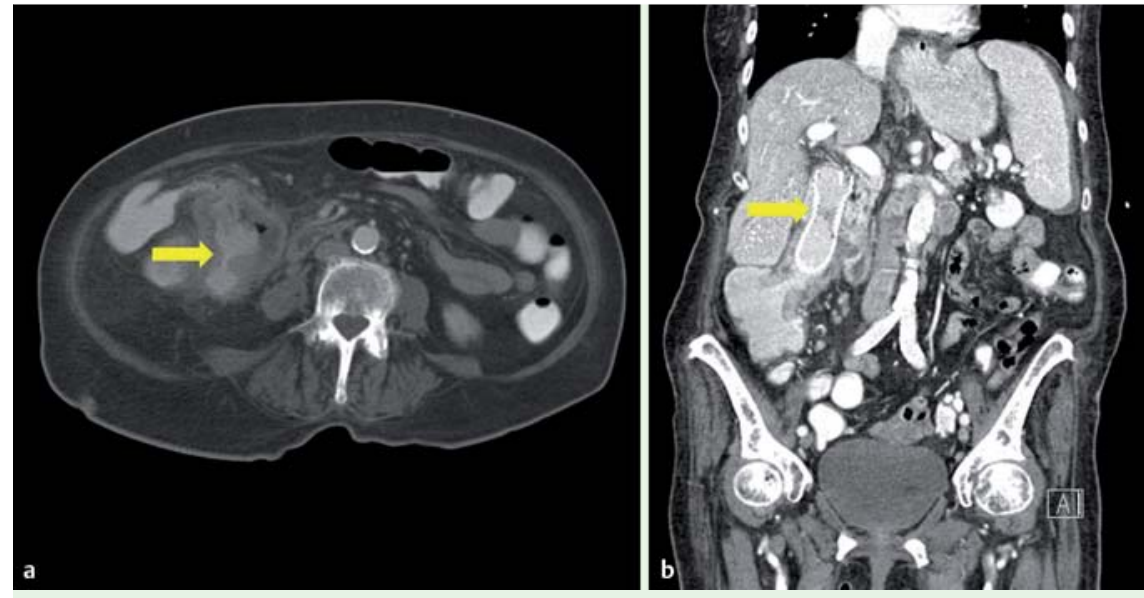

Fig. 1 a Computed tomography (CT) scan showing "apple core" lesion at the hepatic flexure, adjacent to and invading the duodenum. b Coronal CT scan showing colonic self-expanding metal stent extending from right colon into duodenum.

SEMS fistulizing from the right colon into the duodenum. In patients with new symptoms or clinical deterioration after stent placement, the possibility of stent migration or fistulization should be considered.

\section{Endoscopy_UCTN_Code_CPL_1AJ_2AF}

Competing interests: N.J.S.and B.S.have no conflicts to disclose. D.A. is a consultant for Boston Scientific. J.F. is a consultant for Kimberly-Clark, Merit Medical, and Nestlé Nutrition.

\section{N. J. Samadder ${ }^{1}$, J. Fang ${ }^{1}$, D. G. Adler ${ }^{1}$, B. Sklow ${ }^{2}$}

${ }^{1}$ Division of Gastroenterology and Hepatology, Huntsman Cancer Institute and University of Utah, Salt Lake City, Utah, USA

2 Department of Surgery, Huntsman Cancer Institute and University of Utah, Salt Lake City, Utah, USA

\section{References}

1 Deans GT, Krukowski ZH, Irwin ST. Malignant obstruction of the left colon. Br J Surg 1994; 81: $1270-1276$

2 Baron TH. Colonic stenting: a palliative measure only or a bridge to surgery? Endoscopy 2010; 42: $163-168$
3 Meisner S, Gonzalez-Huix F, Vandervoort JG et al. Self-expandable metal stents for relieving malignant colorectal obstruction: short-term safety and efficacy within 30 days of stent procedure in 447 patients. Gastrointest Endosc 2011; 74: 876-884

4 Small AJ, Coelho-Prabhu N, Baron TH. Endoscopic placement of self-expandable metal stents for malignant colonic obstruction: long-term outcomes and complication factors. Gastrointest Endosc 2010; 71: 560 572

5 Blake AM, Monga N, Dunn EM. Biliary stent causing colovaginal fistula: case report. JSLS 2004; 8: 73-75

\section{Bibliography}

Dol http://dx.doi.org/

10.1055/s-0032-1308919

Endoscopy 2012; 44: E233

() Georg Thieme Verlag KG

Stuttgart · New York

ISSN 0013-726X

\section{Corresponding author}

\section{N. J. Samadder, MD, FRCPC}

Division of Gastroenterology and Hepatology Huntsman Cancer Institute and University of Utah 2000 Circle of Hope

Salt Lake City

Utah 84112

USA

Fax: +1-801-581-7476

jewel.samadder@hsc.utah.edu 